\title{
RESEARCH IN THE USE OF A RATING SCALE AS A MEANS OF EVALUATING THE PERSONALITIES OF SENIOR DENTAL STUDENTS ${ }^{1}$
}

\author{
R. K. BROWN, M.S., D.D.S.
}

School of Dentistry, University of Michigan, Ann Arbor, Mick.

English Bagby in his recent work, "The psychology of personality," has given us this introduction to this paper:

"Success in almost every line of vocational endeavor depends upon an ability to make a favorable impression on possible clients or customers. It would be probably agreed that in most professions, the economic importance of the factor of personal charm is greater than technical skill and almost on a par with reputation. Personal charm is, in part, a function of appearance and dress, but neither of these is so significant as habits of speech and conduct.

"Although the development of personality can be controlled in a properly organized educational system, it cannot be said that the modern educational agencies are very effective in this connection. Personality development is left largely to the home and to chance experiences, and typical parents are poorly qualified to administer education of this type."

We recognize the fact that there is a difference between the life of a business man following the marts of trade and that of a professional man who renders health service, but we realize also that certain traits are fundamental and common to both walks of life. The studies of personality that have been made in the business world may be used to establish a working hypothesis for a similar study in professional life.

${ }^{1}$ Read at a session of the Seventh Annual Meeting of the American Association of Dental Schools, in a program coördinated with that of the Eighth General Meeting of the International Association for Dental Research, Royal York Hotel, Toronto, Canada, March 24-26, 1930. (See abstract in this issue: Journal of Dental Research, 1930, x, p. 372.) To be published also in the Proceedings of the American Association of Dental Schools. 
F. A. Moss defines personality capably in his book entitled "Applications of psychology." This work should be in the library of every teacher. He states:

"There was a time in the history of our race when our forefathers were pleased to be able to measure in pounds, it was so much more accurate than guessing. Then they were even more pleased to be able to measure in ounces. The measuring of the physical world is now reduced to a science. It is reasonable to expect that human beings will make similar progress in measuring other humans. We are not at the pound stage in measuring many human traits but in the future we will be able to measure to a high degree of accuracy.

"The most important group of traits the psychologist or human engineer has to measure is the group constituting personality. These traits determine an individual's interest in life; his ability to live socially with his fellow human beings; his success in school and his attainments in his chosen profession. The accurate measurement of these traits is invaluable to the teacher as well as to the business manager or employer in industry."

The frequent occurrence of the word "trait" would call for its definition: A trait is a mode of reaction that tends to differentiate one individual from another. Individuality is the sum total of these measurable differences that makes a man what he is and also shows why he differs from other men. Personality is an individual as perceived by others. It is the individual as he is reflected in the social mirror. Personality consists of an individual's native traits modified or accentuated by his training and environment. Personality is the result of the traits he possesses at birth plus his experiences through life. Man is born with certain components or traits of his personality fixed at birth. These are comprehension, judgment, ability to see relationship, and other traits falling under the general classification of intelligence. The emotional and physical traits also depend on an individual's original make-up at his start in life. Traits of temperament, ethical ideals, and attitudes of conventionality are largely the result of training and environment, and are susceptible to change. The student, during his scholastic life, is in a plastic stage and his personality can be modified with greater ease and facility than is possible after maturity. Traits that are fixed at birth allow of no modification, but traits that are the result of training and environment present the greatest field to the personnel worker. 
The measuring of these traits during early adolescence is a virgin field teeming with possibilities.

The measuring of intelligence may be called almost an exact science. Intelligence, according to Thorndike, is of three kinds:

"1. Abstract intelligence-the ability to deal with ideas.

"2. Social intelligence-the ability to deal with people.

"3. Mechanical intelligence- the ability to deal with mechanical contrivances."

An individual may possess all three kinds in the highest or lowest degree, or may be high in one or two, and low in one or two. The measuring of a man's intelligence is important in a study of his personality, and the possession of a high degree of Thorndike's three kinds of intelligence would make for success. The most successful men do not rank highest in abstract intelligence, and do not receive high grades in school. They rank high in social intelligence, for they please the common people. It has been said that abstract intelligence knows what to do, but social intelligence knows how to get it done.

The application of this outline of intelligence, as given by Thorndike, is valuable to the dentist. Our profession calls for individuals possessed of high degrees of social intelligence with the mechanical and abstract types both necessary, but in less degree. The manner and bearing, as well as the personal appearance, of a professional man should be such that any contacts he makes in his professional or social life will be of the most favorable kind. First impressions are the most lasting. The traits comprising the social aspects of a professional man's personality should receive close study, for these traits make the foundation for success in the conduct of his practice. A dental service rendered by a dentist with a pleasing personality seems to accomplish more than one rendered by a dentist whose impression on his patients is more or less negligible.

Our studies have recognized the fact that scholastic grades are a measure of achievement as well as a measure of intelligence, but we have found that the study of each individual student as to how and why he differs from his fellow students may be of inestimable value to the student in his professional life. The teacher has not fulfilled his obligations to his students until he has made a careful study of their 
personalities. This must be done by some objective means that will weigh or measure each personality by comparison. The results

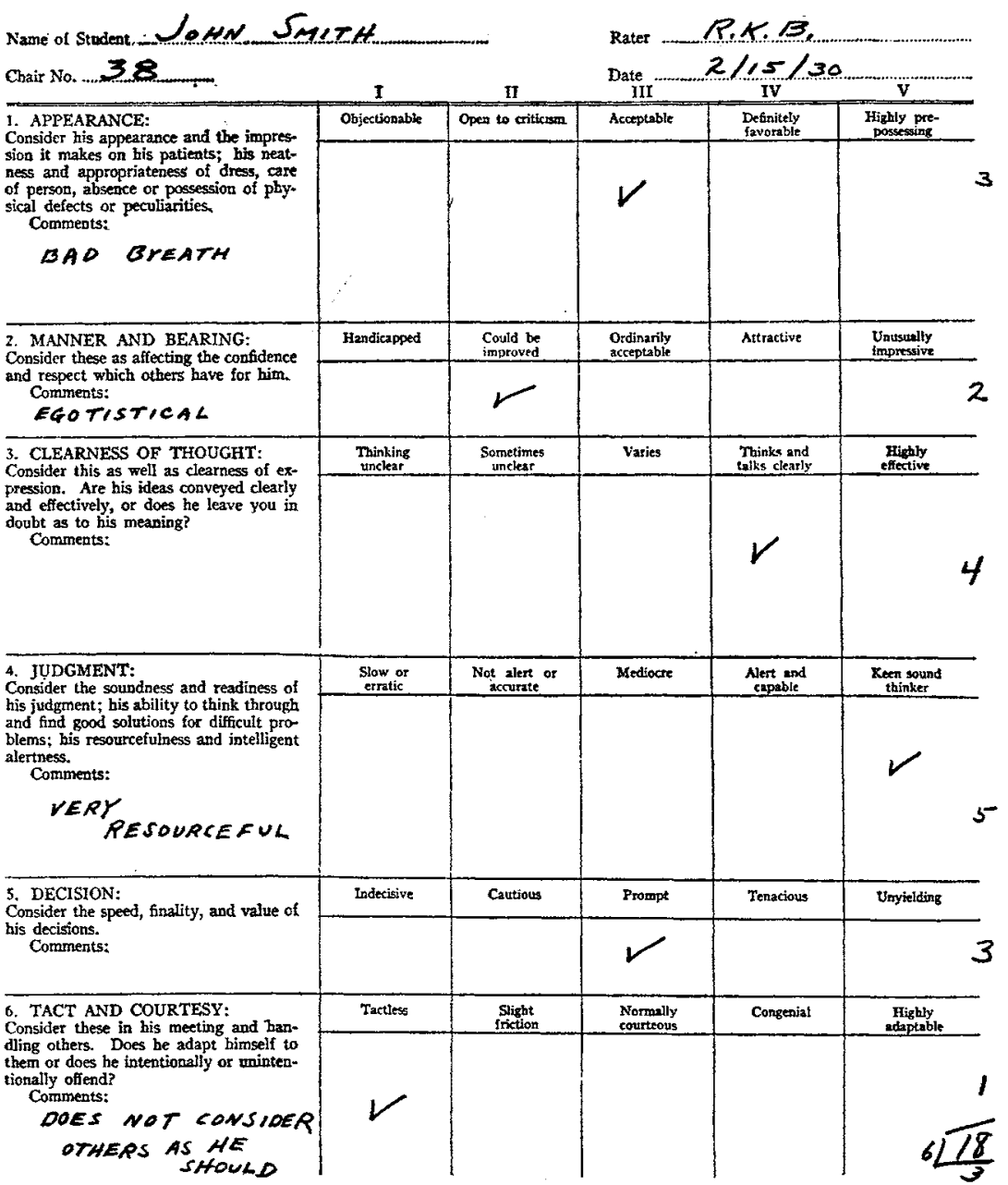

FIG. 1. First page of the graphic rating-scale, showing method of grading a student on the various traits. The average for the first six traits is 3 . The same system is followed in rating the twenty-one traits that were selected.

secured can be used by the student in an effort to modify those of his traits that are too predominant, or too recessive, in order to acquire 
the well rounded personality that will enable him to make effective social contacts during his professional life.

From our studies in collaboration with Professors H. F. Adams and Adelbert Ford, of the Psychology Department in our University, we have chosen the rating scale as a means of measuring traits that have seemed essential to the success of a dentist in his professional life (fig. 1). Similar scales have been in use in the business world, and, as

Traits comprising the rating scale of the senior dental students of the University of Michigan
(1) Appearance
(2) Manner and bearing
(3) Clearness of thought
(4) Judgment
(5) Decision
(6) Tact and courtesy
(7) Attractiveness
(8) Talkativeness
(9) Cheerfulness
(10) Aggressiveness and initiative
(11) Reasonableness
(12) Tolerance and openmindedness
(13) Detail
(14) Diagnostic ability
(15) Type of work
(16) Conscientiousness
(17) Coöperation
(18) Perseverance
(19) Industry
(20) Desire for improvement
(21) Ideals

Professor H. F. Adams has said, "in fact, in any problem where objective ratings of personal traits are necessary, the rating-scale method has been the most reliable one available. Ratings up to the present time are the most accurate measure of any or all traits of personality!"

The graphic rating scale is the most accurate when a group to be rated has more than thirty or forty individuals in it. The order of 
merit type and the Army rating scale will not function as efficiently in the larger groupings. Webb, in his classic monograph, "Character and Intelligence," in the British Journal of Psychology for 1915, lists forty-eight traits that are distinctive and are the component units of personality. These traits fall into five groups:

(1) Physical traits which are bodily attributes, and purely objective

(2) Mental traits, the basis of intellect and intelligence

(3) Social traits dealing with man and his contacts with his fellow men

(4) Temperamental traits comprising the emotional side of an individual

(5) Volitional traits that form the character of an individual

From Webb's forty-eight traits we have listed twenty-one that were considered of importance to a well rounded personality. These are listed in the accompanying summary. Dean Ward, Professor Adams, and myself selected these carefully, and formulated them in a graphic rating-scale. The scale and the statistical methods used in the compilation of our results were checked by Professor H. F. Adams of the Psychology Department in our University.

Each trait selected was required to be:

(1) Unique

(2) Distinct, in that it possessed no overlapping with other traits

(3) Different

The rating scale we use must qualify as follows:

(1) It must be valid; it must measure what it is to measurepersonality.

(2) It must be objective; different raters, applying the scale to the same person, obtain scores or measures that are practically identical.

(3) It must be reliable; when given two or more times to the same group, the two scores have a high coefficient of correlation. Mathematical formulas are used to establish the objectivity and reliability of any given test.

Our rating scale fulfills these qualifications, if it is borne in mind that any system of measurement has three variables:

(1) The measuring instrument itself

(2) The one who uses the instrument

(3) The subject to be measured 
Personality traits are relative, they cannot be measured in terms of any accurate standard such as pounds, or inches. We must measure differences, which are easier to detect than either direction or amount of difference.

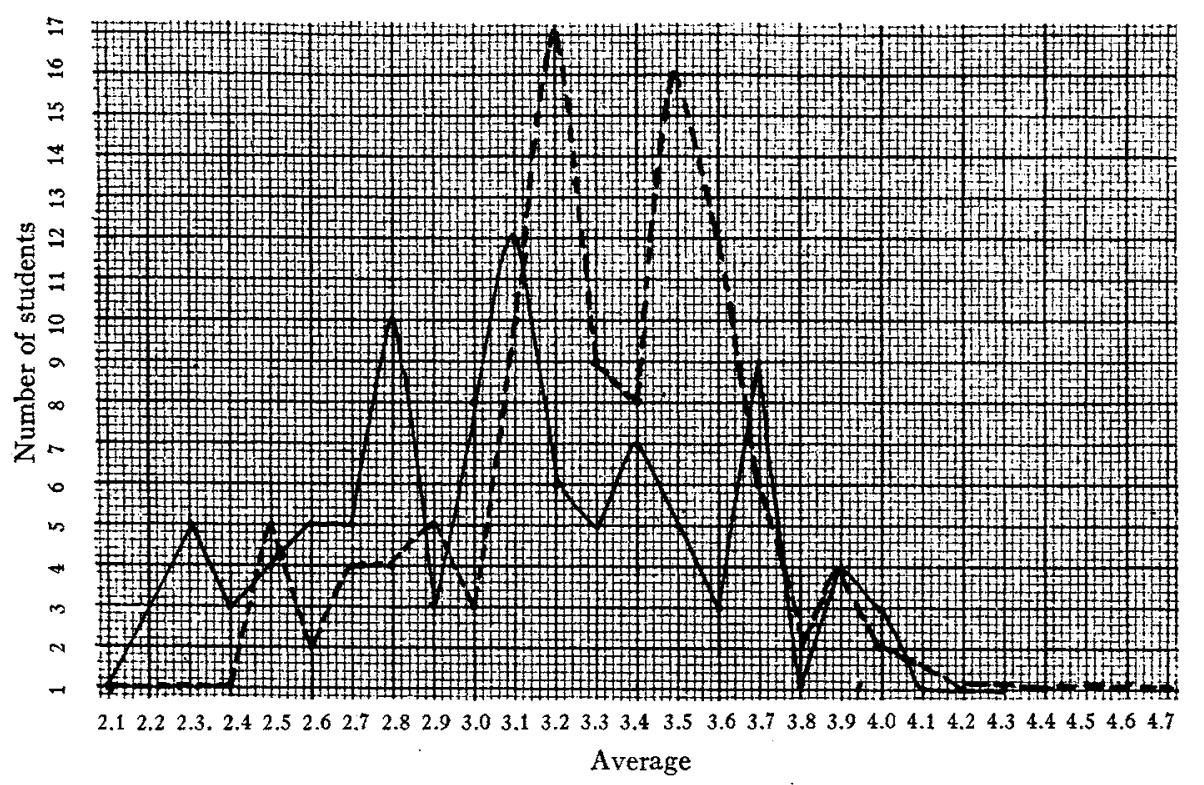

FIG. 2. The personality averages of the classes of 1929 and 1930, plotted as curves. Personality averages ran from 2.1 to 4.7. Each individual, given his personality average, can ascertain his position on this curve.

_._ Class of 1929.

Personality averages:

\begin{tabular}{rrcccc}
1989 & 1930 & Grade & Percent & \multicolumn{2}{c}{ Ranges } \\
10 & 11 & A & 10 & $3.9-4.3$ & $3.8-4.7$ \\
18 & 18 & B & 20 & $3.5-3.8$ & $3.6-3.7$ \\
41 & 50 & C & 40 & $2.9-3.4$ & $3.2-3.5$ \\
20 & 28 & D & 20 & $2.6-2.8$ & $2.6-3.1$ \\
13 & 8 & E & 10 & $2.1-2.5$ & $2.1-2.5$ \\
102 & 115 & & & &
\end{tabular}

The rating of a class is carried through by two or more raters. The average class-personality is found, and a curve is plotted so that each student, upon receiving his master rating-scale, knows his position on 
the personality curve with respect to his fellow classmates (fig. 2). A curve is plotted that shows the class-average of each trait, from which the student may ascertain the traits in which he ranks high and those in which he ranks low in comparison to his class as a whole (fig. 3). The scale will give him a cross section of his personality as seen by his teachers. If he desires to do so, the student can profit materially

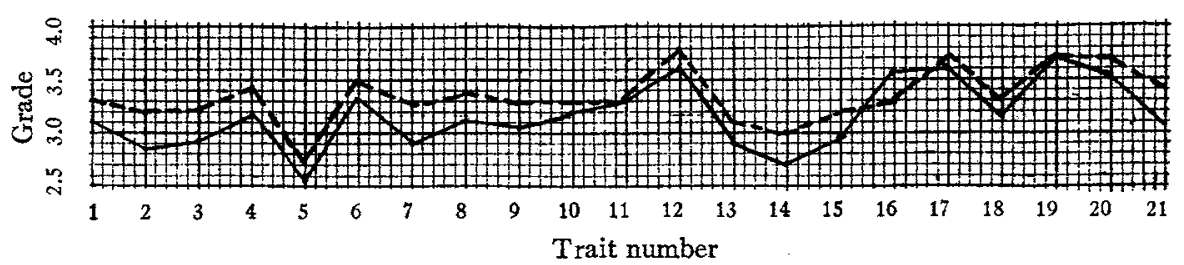

Fra. 3. The class average for each of the twenty-one traits, plotted as a curve. The results for the classes of 1929 and 1930 were used. Each student can compare his grade on each trait with the average grade of his class for that trait. He can ascertain those traits in which he is below, and those above, the rest of his class. This gives him a working basis on which to modify his personality.

- Class of 1929.

_... " " " 1930.

Class average for each trait: 1929 and 1930:

\begin{tabular}{|c|c|c|c|}
\hline & \multicolumn{3}{|c|}{ Class } \\
\hline No. & 'T29 & & \\
\hline 1 & 3.1 & - & 3 \\
\hline 2 & 2.9 & - & \\
\hline 3 & 2.9 & - & \\
\hline 4 & 3.1 & $\rightarrow$ & \\
\hline 5 & 2.6 & - & \\
\hline 6 & 3.3 & - & \\
\hline 7 & 2.9 & - & \\
\hline 8 & 3.1 & - & \\
\hline 9 & 3.1 & - & \\
\hline 10 & 3.2 & - & \\
\hline 11 & 3.3 & - & \\
\hline
\end{tabular}

$\begin{array}{lr}\begin{array}{c}\text { Trait } \\ \text { No. }\end{array} & \text { Class } \\ 12 & 3.6-30 \\ 13 & 2.9-3.8 \\ 14 & 2.7-3.1 \\ 15 & 3.0-3.0 \\ 16 & 3.5-3.3 \\ 17 & 3.6-3.7 \\ 18 & 3.2-3.3 \\ 19 & 3.7-3.7 \\ 20 & 3.6-3.7 \\ 21 & 3.2-3.4\end{array}$

from this knowledge by modifying his personal traits so as to bring him nearer the ultimate personality desired and sought by all of us.

The teacher has one more instrument that will measure the abilities of his students. Character and personality are of equal importance with ability in the achievement of knowledge and skill. The estimation of these will give us a firmer ground upon which to stand in making the decision as to whether a man possesses the qualifications to become a graduate. 
I have found that the scale has another distinct value. As director of the operative department of bur School, it is important for me to evaluate the ability of the different teachers on my staff to observe and to judge. By comparing the ratings of the different staff members who have rated the students, I secure a valuable insight into the ability of each teacher to evaluate the individual student, and I am able also to place relative values on the judgments and observations of these teachers as they pertain to many problems that arise during the scholastic year in the conduct of the operative clinic.

We hope, in the future, to be able to give correlations between scholastic and clinical grades, personality ratings, and postgraduate success in practice. These results can be secured only after a certain lapse of time, but may prove very interesting and valuable. A fair amount of practical information as to a graduate's success in practice can be ascertained by the use of a "hidden" questionnaire, mailed to graduates after two, five, or ten years of practice, depending on the information desired. The evaluation of personality should begin in the first year of the dental curriculum, so that the student can have sufficient time to develop his personality under competent guidance, for we are aware that such changes are made with greater facility in youth than in later life.

In conclusion allow me to present a classical definition of personality. It is from the pen of that great scholar and educator, President C. W. Eliot of Harvard:

"Every one now believes that there is in man an animating, ruling, characteristic essence or spirit, which is himself. This spirit, dull or bright, petty or grand, pure or foul-looks out of the eyes, sounds in the voice, and appears in the manners of each individual. It is what we call personality."

\section{BIBLIOGRAPHY}

"Ways of the Mind," H. F. Adams: Scribners.

"Psychology of Personality," English Bagby: Henry Holt.

"Training and Selection of Men," Donald A. Laird: McGraw-Hill.

"Exploring Your Mind," A. E. Wiggam: Bobbs Merrill.

"Applications of Psychology," Fred A. Moss: Houghton-Miftlin.

"Teaching of Ideals," W. W. Charters: MacMillan. 